\section{Box 1: Ranking big pharma}

The Access to Medicine Index seeks to measure whether the worldís major pharmaceutical firms are good corporate citizens, using 8 criteria on a scale of 1-5: management, influence, research and development, patenting, capacity, philanthropy, pricing and drug donations. In 2008, organizers assessed 20 firms. In descending order (with their ratings on the scale) they were:

1. GlaxoSmithKline PLC (4.5)

2. Novo Nordisk A/S (3.9)

3. Merck \& Company Inc. (3.9)

4. Novartis AG (3.9)

5. Sanofi-Aventis (3.9)

6. AstraZeneca PLC (3.7)

7. Roche Holdings Ltd. (3.6)

8. Johnson \& Johnson (3.6)

9. Bayer Schering Pharma AG (3.5)

10. Eli Lilly \& Company (3.5)

11. Bristol-Myers Squibb Co. (3.0)

12. Abbott Laboratories Inc. (2.9)

13. Merck KgaA AG (2.8)

14. Cipla Ltd. (2.7)

15. Gilead Sciences Inc. (2.7)

16. Ranbaxy Laboratories Ltd. (2.7)

17. Pfizer Inc. (2.6)

18. Wyeth (2.1)

19. Teva Pharmaceutical Ltd. (1.8)

20. Schering-Plough Corp. (1.3)

Source: Access to Medicine Index.

Vancouver-based corporate responsibility expert Coro Strandberg is impressed by the index's comprehensiveness and user-friendliness.

But as with other efforts to weigh corporate social responsibility, she cautioned that if the index is to grow into a trusted measuring tool, it will have to be based on data that is current and verifiable by third parties. For now, though, Strandberg stresses that it's a valuable step that the index has been launched and is freely available on the Internet to those wanting to compare the progress of major drug manufacturer's in achieving the criteria.

Leereveld forecasts that "the criteria will be sharper every year. ... I know that we have achieved goals if all measured companies have adapted their policy to the policies of leading companies."

Strandberg notes that such indices can help socially minded investors and consumers make ethical purchasing decisions and ultimately those decisions will affect the corporate behaviour of the manufacturers.
But some fear it could evolve into little more than a public relations tool for big pharma.

Tim Reed of the Amsterdam-based Health Action International is concerned that the index may just be "scratching the surface of corporate social responsibility." The bulk of the data used to construct the index is self-reported, he notes, adding that robust data provided by local consumers and patients would be a valuable addition. Yet, many would maintain that simply establishing the index has the potential to aid in drugs becoming more accessible in the developing world.

The first index identifies UK-based GlaxoSmithKline as the current industry leader when it comes to improving access to drugs and vaccines. - Alan Cassels, Victoria, BC

DOI:10.1503/cmaj.081135

Dr. Alan Cassels is a drug policy researcher at the University of Victoria and a selfdescribed pharmaceutical skeptic. His most recent book was The ABCs of Disease Mongering: An Epidemic in 26 Letters (CMAJ 2008:179[1]:58-9).

\title{
Health Canada's investment in new post- market drug surveillance network a "pittance"
}

Published at www.cmaj.ca on July 16, 2008. Print version revised.

I $\mathrm{n}$ the wake of mounting public concern about prescription drug safety and high-profile drug withdrawals, Health Canada has announced a \$1 million investment in an independent research network to study the safety of prescription drugs taken by Canadians.

But observers say that the investment, announced in July 2008, falls far short of what is needed. A business plan produced for the proposed network last year estimated annual operating costs to be $\$ 20.6$ million.

Parliament's Standing Committee on Health called on the government in June 2008 to "immediately" establish the network, which would link researchers around the country to produce timely reports that track the impact of drug use in the "real world" and hence help protect Canadians from the unanticipated adverse effects of prescription drugs.

Dr. Carolyn Bennett, Member of Parliament for St. Paul's, Toronto and a committee member, was "thrilled" the network is being acknowledged, but dismissed the \$1-million investment as a "pittance... just a little nod, with no assurance that another $\$ 20$ million will be forthcoming."

Post-Market Surveillance of Pharmaceuticals (June 2008), the Parliamentary committee's 54-page report, noted that Health Canada's proposed new "life cycle" approach to regulating prescription drugs (Bill C51) would ramp up the need for scrutiny of how drugs are actually used after they are approved for marketing.

Drugs are now assessed for safety and efficacy before they are approved for marketing, but the assessment is based on clinical trials conducted with limited numbers and types of patients. It is widely acknowledged that once on the market, drugs are taken by patients and disease groups that were never assessed, leaving them at risk for unexpected risks. A modern regulatory system is one that "continuously assesses a product's risks and benefits, both before and after it reaches the market," states the federal Food and Consumer Product Safety Action Plan.

Around the world, countries are moving to establish systems to track the safety and effectiveness of drugs after they are marketed, but a key stumbling block is "sheer political will, because you have to put money towards this," says internationally renowned drug researcher Dr. David Henry, who is now the president of the Institute of Clinical Evaluative Sciences in Toronto, Ontario.

"This is such an important issue. A lot of drugs seem okay and are later found to have serious adverse effects, like [rofecoxib] Vioxx [which was withdrawn from the Canadian market in 2005] and the diabetes drug [rosigli- 
tazone] Avandia," he says. "You need a system that is capable of detecting an increase in adverse reactions that are not, like sudden fatal liver disease, well recognized," he says. For example, heart attacks and strokes could be drug reactions, but would be recognized as such only through formal large-scale surveillance, not through reports on individual patients, he said.

Henry, who moved from Australia to Canada this year, says Health Canada's announced investment is "necessary but not sufficient.... I can only take it as an article of faith that more money will follow, that this represents an enduring commitment." The $\$ 1$ million is to support a "detailed implementation plan," Health Canada spokesperson Stéphane Shank stated in an email interview. It's not yet clear whether the provinces will kick in monies but Shank noted that the 2008 federal budget allocated about $\$ 119$ million over 5 years for health product safety.

Canada is in a very good position internationally to set up the proposed drug safety network because detailed data sets that are available from provinces can be linked; the high quality of researchers in epidemiology, pharmacology and methodology; and Canada's success in addressing privacy concerns through the use of anonymized data, Henry said.

Canadians now spend about $\$ 22.5$ billion annually on prescription drugs, with public drug plans picking up about half the tab. In 2004, about $\$ 38$ million was spent on the premarket drug ap-

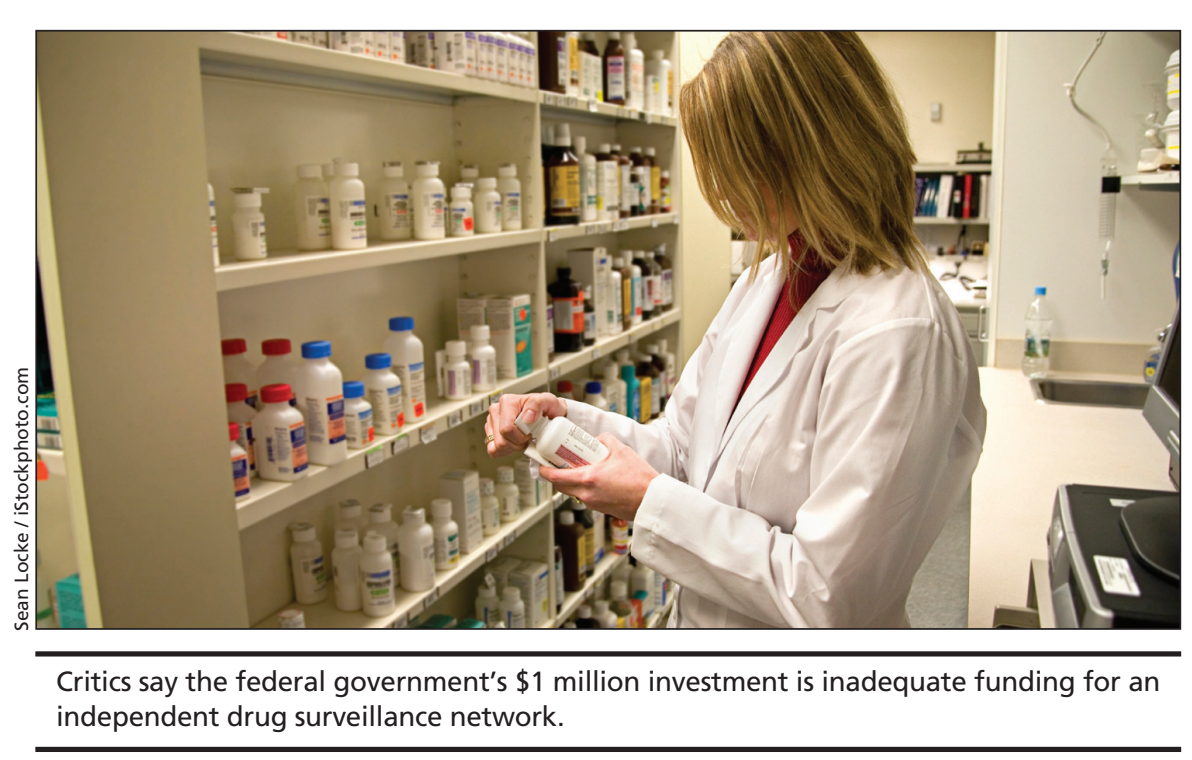

Critics say the federal government's \$1 million investment is inadequate funding for an independent drug surveillance network.

proval process (a substantial portion of that contributed by user fees paid by pharmaceutical companies), while the budget for the Marketed Health Products Directorate, charged with postmarket surveillance for all health products (including drugs), was just $\$ 8$ million.

Canadian researchers, many of whom have been working together for several years on issues related to creating such a network, are heartened by this week's announcement. Sustained and predictable funding will be essential for the network to be attractive to the best scientists and research staff, notes Prof. Steve Morgan, who heads the program on pharmaceutical policy at the University of British Columbia's Centre for Health Services and Policy. "It can't be done in a series of one-off, 1-year projects. It has to be 5 years or more to create a community of practice that is going to be engaged in this in a meaningful way."

Henry says that key to the success is for provinces to make data available to researchers, and if that takes place "something can happen quite quickly." A backgrounder from Health Canada notes that "coordinated national collaboration and progress in addressing this important issue [postmarket surveillance] was difficult." — Ann Silversides, CMAJ

\section{DOI:10.1503/cmaj.081099}

Note: As a freelance writer, Ann Silversides attended internal workshops and wrote reports on several initial meetings of stakeholders seeking to establish the Drug Effectiveness and Safety Network.

\section{Briefly}

Pharma gifts: The Pharmaceutical Research and Manufacturers of America have crafted a new voluntary guideline that asks member companies to stop giving doctors pens, pads, mugs and other trinkets. Restaurant meals on the sales representative's credit card are also frowned upon. Rather, the sales reps should bring lunches to doctor's offices, or have them catered. The revised Code on Interactions with Healthcare Professionals (www.phrma.org) does not disdain cash payments to physicians in the form of speaking and consulting fees, although such industry largesse was recently disavowed by the Association of American Medical Colleges due to the perception that industry handouts are influencing therapeutic decisions and compromising the medical profession's reputation (CMAJ 2008;178[13]:1651-2 and CMAJ 2008;179[3]:225-6).

Lab standards: The Canadian Association of Pathologists wrapped up its annual meeting in July 2008 by calling on the federal government to establish national standards and protocols for pathologists, as urged by experts in CMAJ (CMAJ 2008;179[2]:125-6 and CMAJ 2008;178[12]:1523-4). The association also released a 5-point action plan calling for "an appropriately resourced national system." It also proposed mandatory certification for all laboratory tests and the creation of a national body to accredit labs.

MAPLES fallout: MDS Inc. has served Atomic Energy of Canada Ltd. with notice that is seeking arbitration — and simultaneously filing a $\$ 1.6$ billion lawsuit alleging negligence for breaching its contractual obligations by pulling the plug on the once-ballyhooed, but since discredited Multipurpose Applied Physics Lattice Experiment (MAPLES) reactors, which had underpinned plans to ensure a long-term national supply of medical isotopes (CMAJ 2008;178[13]:1648 and CMAJ 2008;178[7]:813-4). — Wayne Kondro, CMAJ

DOI:10.1503/cmaj.081141 